\title{
How we approach coagulopathy with vascular anomalies.
}

\author{
Joana Mack ${ }^{1}$ and Shelley Crary ${ }^{2}$ \\ ${ }^{1}$ Arkansas Children's Hospital \\ ${ }^{2}$ University of Arkansas for Medical Sciences
}

April 8, 2021

\begin{abstract}
Some vascular anomalies can present with challenging hematologic aberrations. Kaposiform hemangioendothelioma (KHE) may be complicated with Kasabach-Merritt phenomenon (KMP) and stagnant blood flow in slow flow malformations can promote activation and consumption of coagulation factors which results in bleeding and clotting known as localized intravascular coagulopathy (LIC). These patients can experience significant morbidity secondary to pain due to thrombosis and are at higher risk of hematologic complications during surgical procedures. No standard of care has been established to prevent or manage these complications. This review focuses on the management of coagulopathy in children and adults with vascular anomalies.
\end{abstract}

\section{How we approach coagulopathy with vascular anomalies}

Joana M. Mack, MD ${ }^{\mathrm{a}, \mathrm{b}}$ | Shelley E. Crary, MD, MS ${ }^{\mathrm{a}, \mathrm{b}}$

${ }^{a}$ Department of Pediatrics, Division of Hematology/Oncology, University of Arkansas for Medical Sciences. ${ }^{\mathrm{b}}$ Arkansas Children's Hospital.

\begin{abstract}
Some vascular anomalies can present with challenging hematologic aberrations. Kaposiform hemangioendothelioma (KHE) may be complicated with Kasabach-Merritt phenomenon (KMP) and stagnant blood flow in slow flow malformations can promote activation and consumption of coagulation factors which results in bleeding and clotting known as localized intravascular coagulopathy (LIC). These patients can experience significant morbidity secondary to pain due to thrombosis and are at higher risk of hematologic complications during surgical procedures. No standard of care has been established to prevent or manage these complications. This review focuses on the management of coagulopathy in children and adults with vascular anomalies.
\end{abstract}
Abbreviations
KHE - Kaposiform hemangioendothelioma
KMP - Kasabach-Merritt phenomenon
$\mathrm{PT}$ - prothrombin time
aPTT - activated partial thromboplastin time
VTE - venous thromboembolism
LIC - localized intravascular coagulopathy
CBC - complete blood count
ITP - idiopathic thrombocytopenia 
IVIG - intravenous immunoglobulin

CT - computed tomography

MRI - magnetic resonance imaging

KTS - Klippel-Trenaunay syndrome

LMWH - low-molecular-weight heparin

MOCA - mechanochemical ablation

DIC - disseminated intravascular coagulopathy

KLA - Kaposiform Lymphangiomatosis

MLT - multifocal lymphangioendotheliomastosis with thrombocytopenia

FDA - Food and Drug Administration

DOAC - Direct oral anticoagulant

\section{1 | INTRODUCTION}

Kasabach-Merritt phenomenon (KMP)

Kasabach-Merritt phenomenon a severe coagulopathy disorder characterized by severe thrombocytopenia (platelet count $<50,000 / \mathrm{mm}^{3}$ ), elevated D-dimer, hypofibrinogenemia and prolonged prothrombin time (PT) and activated partial thromboplastin time $(\mathrm{aPTT})^{1}$. Anemia may be present especially if bleeding symptoms. KMP is known to occur as an association with specific vascular tumors - Kaposiform hemangioendothelioma (KHE) or Tufted Angioma (TA). KHE is a rare, life-threatening vascular tumor and frequently presents with KMP in up to $70 \%$ of cases $^{2}$. The KHE lesion most commonly presents as an enlarging, firm mass with red-purple discoloration if the skin is involved, typically presenting shortly after birth or during early childhood. When associated with KMP it is generally rapidly enlarging, warm to touch and very purpuric in coloration. Not all KHE have cutaneous involvement and diagnosis may be delayed ${ }^{2}$. Often patients without cutaneous involvement present with signs of thrombocytopenia and mucocutaneous bleeding. Intrathoracic and retroperitoneal KHE may be at higher risk for KMP as these lesions are often very large and expansive ${ }^{1-3}$. The etiology of the coagulopathy in KHE is not well-understood. It likely involves platelet trapping within the vascular lesion followed by activation of the platelets and further platelet aggregation ${ }^{3,4}$. This ultimately leads to activation of the coagulation cascade and consumption of factors. Intralesional thrombi and subsequent hemorrhage leads to the clinical findings of "growth", deepening of color and warmth of the lesions ${ }^{1}$.

\section{Localized Intravascular Coagulopathy}

Slow-flow vascular malformations, especially those with a large venous component can frequently be complicated by intralesional thrombosis and if ectatic vessels are connected to larger feeding veins this can put patients at risk for venous thromboembolism (VTE) ${ }^{5-11}$. Although the mechanism is not fully elucidated, venous stagnation can lead to activation and consumption of coagulation factors and platelets and result in localized intravascular coagulopathy (LIC). Pain is often correlated to LIC and is a common symptom of slow-flow vascular malformations resulting in decrease of quality of life and worse outcomes ${ }^{12,13}$. Pain in this group is complex occurring in the acute and chronic setting often associated with intralesional thrombi. The pain may also involve several contributing factors which include chronic venous insufficiency, inflammation, infection, arthritis, and neuropathic pain ${ }^{14}$.

LIC may worsen during a surgical or interventional procedure where the abnormal vasculature is perturbed leading to post-operative bleeding or thrombotic complications. Large excisions or prolonged intravascular procedures seem to be the highest risk procedures. There are no evidence-based guidelines for peri-operative management of LIC to mitigate the risk of hematologic complications. Sirolimus has been shown to reduce the coagulopathy and for minor procedures these patients may not require additional anticoagulation ${ }^{15}$. 
However, for complex surgical procedures and in patients with laboratory evidence of LIC, anticoagulation before and after the procedure may be warranted ${ }^{16}$.

Recognizing pediatric and adult patients with vascular tumors and malformations that are predisposed to coagulopathy is important. The rapidly growing field of surgical and medical management of vascular anomalies include medications that may improve or worsen the coagulopathy. Early identification will help improve outcomes in this patient population. Although there are no consensus guidelines, this review will help provide guidance in the therapeutic approach for management of coagulopathy in patients with vascular anomalies based on our current practice and review of the available literature.

\section{2 | DIAGNOSTIC APPROACH}

Appropriate management relies on accurate diagnosis. Historical data of the vascular malformation such as first appearance, growth, and aggravating factors are important. Physical exam, imaging and laboratory evaluation are essential in diagnosis and determining what treatment, if any, is needed. Conventional coagulation parameters that include complete blood count (CBC), prothrombin time (PT), activated partial thromboplastin time (aPTT), fibrinogen, and D-dimer vary in specific vascular anomalies that are predisposed to coagulopathy (Table 1 ).

\section{3 | CONSULTATION WITH THE HEMATOLOGIST}

\section{1 | Case 1: KHE with KMP}

Patient 1 presented at 3 months of age with petechiae and purpura on his extremities. He had been diagnosed with an upper respiratory infection and placed on a 10-day course of antibiotics within the previous 2 weeks from presentation. Upon presentation to the emergency department his platelet count was $2,000 / \mathrm{mm}^{3}$. Given his presentation and recent viral illness, he was initially diagnosed with idiopathic thrombocytopenia (ITP) and was given intravenous immunoglobulin (IVIG) $1 \mathrm{~g} / \mathrm{kg}$. The following day his platelets remained at $11,000 / \mathrm{mm}^{3}$ and hemoglobin declined to $8.7 \mathrm{~g} / \mathrm{dL}$. [Figure 1]

Ultrasound of the abdomen was performed as there was concern for splenomegaly and due to the atypical ITP presentation at this age. A retroperitoneal mass was discovered that appeared to be coming from the tail of the pancreas. Computed tomography $(\mathrm{CT})$ was performed for better visualization and confirmed a $6.2 \mathrm{~cm} \times 3 \mathrm{~cm}$ mass with heterogeneous attenuation encompassing the splenic artery and extending into celiac axis. Patient went to the operative room for biopsy of the lesion. Prior to the procedure he was transfused platelets and platelet count increased to $55,000 / \mathrm{mm}^{3}$. He had no bleeding complications with the procedure. Coagulation panel was obtained on hospital day 2 and revealed fibrinogen of $163 \mathrm{mg} / \mathrm{dL}$ and elevated d-dimer of 22. This was repeated on hospital day 6 and fibrinogen was $299 \mathrm{mg} / \mathrm{dL}$ and d-dimer 21.7 .

Pathology was consistent with KHE. Given the thrombocytopenia and elevated D-dimer he was diagnosed with KMP and prednisone $2 \mathrm{mg} / \mathrm{kg} /$ day was initiated. Consent was obtained from the family and he was started on weekly intravenous vincristine $0.05 \mathrm{mg} / \mathrm{kg}$. His fibrinogen initially dropped to $90 \mathrm{mg} / \mathrm{dL}$ and he was given cryoprecipitate, but his platelets began to improve after only a couple of days of corticosteroids. Over the subsequent 4 weeks his fibrinogen fluctuated from $86 \mathrm{mg} / \mathrm{dL}$ to $178 \mathrm{mg} / \mathrm{dL}$ and his platelets from $37,000 / \mathrm{mm}^{3}$ to $206,000 / \mathrm{mm} 3$. Steroids were very slowly weaned and were discontinued once fibrinogen and platelets had consistently normalized. The lesion was imaged with magnetic resonance imaging (MRI) every

3 months and saw initial shrinkage but then remained stable. He was treated with 3 12-week cycles of vincristine and at the end of therapy, his blood counts were normal and the KHE lesion was stable at 1.4 $\mathrm{cm} \times 4 \mathrm{~cm}$. He is now $5 \frac{1}{2}$ years off therapy and doing well with no recurrent of the KMP and no evidence of progression of the tumor.

\subsection{Case 2: Pain and VTE risk in complex vascular malformations}

Patient 2 is a 15-year-old male with extensive Klippel-Trenaunay syndrome of the left lower extremity. Her vascular malformation includes a significant ectatic slow-flow vessel. Growth, infections and pain have 
been fairly controlled since starting sirolimus 3 years ago. Over the past year, she has become more active in sports. She presented with localized left leg pain with palpable knots and an elevated D-dimer (4 times ULN) consistent with LIC. A short 2 week treatment with low-molecular-weight heparin (LMWH) was initiated which resulted decreased pain, resolution of palpable knots, and decreased D-dimer. However, within a couple of weeks of completing the course of anticoagulation, her pain and D-dimer elevation recurred. A left lower extremity recurrent thrombus was confirmed on ultrasound. After a 12 week course of anticoagulation, risks and benefits were discussed and she was transitioned to rivaroxaban. Anticoagulation was continued due to patient's recurrent VTE and increased risk of thrombosis due to the extensive ectatic slow-flow vessel. She is currently managed on sirolimus and rivaroxaban with plans to decrease her VTE risk by obliterating the ectatic slow-flow vessel through mechanicochemical ablation with ClariVein.

\subsection{Case 3: Perioperative management in patient with LIC}

Patient 3 is a 25-year-old male with a history of multifocal venous malformation of the chest wall, back, retroperitoneum, abdomen, scrotum, buttocks and right lower extremity. [Figure 2] He had a history of significant bleeding after a knee surgery (synovectomy) at age 15 years complicated by a report of disseminated intravascular coagulopathy (DIC). Upon presentation to hematology 4 years ago he had the following labs: Platelet count 121,000/mm3, PT $13.6 \mathrm{sec}$, aPTT $27 \mathrm{sec}$, fibrinogen $<80 \mathrm{mg} / \mathrm{dl}$, d-dimer $24.22 \mathrm{mg} / \mathrm{L} \mathrm{FEU.}$ He had significant pain and hard nodules in his malformation and was started on rivaroxaban 10mg daily and titrated up to $20 \mathrm{mg}$ daily. Sirolimus was subsequently added and pain and coagulation labs improved some. He underwent a surgical debulking of a lesion on his back and developed a significant hematoma at the surgical site while on LMWH $1 \mathrm{mg} / \mathrm{kg} /$ dose twice daily. Due to the persistent pain he was scheduled for glue embolization and resection followed by sclerotherapy of several of the malformations on his back and chest. Prior to this procedure he had the following labs: platelet count 164,000/mm3, fibrinogen 148 $\mathrm{mg} / \mathrm{dl}$, d-dimer $6.37 \mathrm{mg} / \mathrm{L}$ FEU. He was switched to LMWH 40mg once daily for the procedure given his previous history of bleeding complication. He tolerated procedure without bleeding complications but labs after procedure showed d-dimer $>30 \mathrm{mg} / \mathrm{L} \mathrm{FEU}$, fibrinogen $<80 \mathrm{mg} / \mathrm{dl}$ and platelets $77,000 / \mathrm{mm} 3$. LMWH was increased to therapeutic dosing and he received several transfusions of cryoprecipitate and platelets for some bleeding from the wound and development of a large flank wall hematoma. On therapeutic LMWH his platelets improved to $244,000 / \mathrm{mm} 3$, fibrinogen to $260 \mathrm{mg} / \mathrm{dl}$ and d-dimer to $8.92 \mathrm{mg} / \mathrm{L}$ FEU and the bleeding ceased. He is currently managed on ongoing rivaroxaban $20 \mathrm{mg}$ daily with normal platelet count and fibrinogen level and d-dimer is $0.79 \mathrm{mg} / \mathrm{L} \mathrm{FEU.}$

\section{4 | MANAGEMENT}

\section{1 | KMP}

Diagnosis of KMP

Diagnosis of KHE is often made by clinical findings, imaging (usually MRI or ultrasound) and hematological findings alone ${ }^{17}$. Biopsy with histologic confirmation is the gold standard; however, biopsy is often difficult or dangerous due to the coagulopathy and clinical diagnosis must suffice. For atypical lesions, biopsy can be safely performed after administration of blood products such as platelets, fresh frozen plasma or cryoprecipitate.

\section{Differential diagnosis of coagulopathy in vascular anomalies}

It is important to be certain of the diagnosis as clinically the differential diagnosis of a vascular lesion with coagulopathy may overlap with other conditions (Table 1). Kaposiform lymphangiomatosis (KLA) is a very rare lymphatic disorder that usually presents with multifocal or diffuse involvement of the mediastinum, lungs, bones and abdomen. These patients can have very severe thrombocytopenia with coagulopathy similar to KMP ${ }^{18-20}$. They do not typically respond to corticosteroids. They can be differentiated from KHE by the presence of a somatic activating NRAS mutation which have not been shown in $\mathrm{KHE}^{21}$. Both KLA and KHE have elevation of angiopoetin-2 (Ang-2 $)^{22}$ but this may be a helpful biomarker to distinguish from other vascular lesions. Another vascular disorder that may present with bleeding and thrombocytopenia 
is multifocal lymphangioendotheliomatosis with thrombocytopenia (MLT). MLT, however, does not usually have the findings of intravascular coagulopathy (hypofibrinogenemia, elevated d-dimer, prolonged PT/aPTT) and bleeding typically occurs directly from the lesions present in the gastrointestinal tract or lungs ${ }^{23,24}$. Some congenital hemangiomas may also present with a mild consumptive coagulopathy, but it is typically not as severe, and the congenital hemangiomas do not continue to enlarge after birth as the KHE with KMP typically $\mathrm{do}^{25}$. Large venous malformations may also have evidence of LIC presenting with very elevated d-dimer and, when severe, thrombocytopenia and hypofibrinogenemia ${ }^{26,27}$. These lesions should be differentiated from KHE with imaging findings.

\section{Management of coagulopathy of KHE}

Management of KMP is emergent as it may result in life-threatening bleeding complications (Table 2). Although surgical resection can result in cure, this is often unsafe due to coagulopathy and the extensive, infiltrative nature of the KHE. Embolization has also been successful in select cases ${ }^{28}$. However, medical management by a hematologist is currently the standard in the US. There are no randomized clinical trials for KHE and therefore most of the evidence for treatment is through expert opinions or observational studies. Historically corticosteroids have been successful in initial management of KMP but is rarely successful as monotherapy ${ }^{29}$. Due to adverse effects of prolonged corticosteroids in infants and young children, the dose should be weaned rapidly once evidence of control of coagulopathy. Vincristine in combination with corticosteroids has been recommended in previous consensus statements to be the treatment of choice but has recently been supplanted by sirolimus (plus corticosteroids) as the first line choice ${ }^{17,30,31}$. A randomized control trial of vincristine versus sirolimus was discontinued early due to poor accrual primarily because of the provider and family preference of sirolimus despite lack of rigorous evidence. Vincristine is now primarily preferred for refractory or recurrent cases. Topical sirolimus or tacrolimus have been shown in small studies to be beneficial for superficial cutaneous lesions ${ }^{32,33}$. Antiplatelet therapy such as aspirin or ticlopidine in combination with vincristine have also shown success ${ }^{34-37}$. Although it appears counterintuitive to most hematologists to treat a patient with severe thrombocytopenia with antiplatelet agents, this may be an option to prevent continued platelet aggregation and activation as this is the primary trigger for the coagulopathy. Antiplatelet therapy is used more frequently in European centers and has not been widely adopted in North American centers. However, for cases refractory to corticosteroids and/or sirolimus or recurrent KMP upon tapering current medical therapy, antiplatelet therapy should be considered as an adjuvant. Some reports of fibrinolytic agents have been reported ${ }^{38}$, but we do not currently routinely recommend these therapies.

Supportive care is critically important in the early management of KMP. Platelet transfusions should be avoided unless indicated for severe bleeding or prior to biopsy or resection ${ }^{17}$. Platelets contain pro-angiogenic growth factor which may potentiate growth of the vascular lesion. In addition, the transfused platelets will be further trapped within the lesion resulting in further immediate growth and will promote activation and consumption of coagulation factors ${ }^{39,40}$. It is generally accepted that cryoprecipitate or fresh frozen plasma be transfused for active bleeding or prior to procedures if the fibrinogen is less than $100 \mathrm{mg} / \mathrm{dL}$. Routine administration of cryoprecipitate for asymptomatic mild hypofibrinogenemia is not indicated. Transfusion of packed red blood cells is indicated for severe or symptomatic anemia ${ }^{17}$.

\section{2 | Risks and management of LIC}

\section{Pain management}

Treatment with compression is usually the first intervention for pain secondary to a vascular malformation. Subsequently, systemic treatment of pain is targeted at associated phleboliths and localized intra-lesion thrombosis. Aspirin, an antiplatelet agent, was initially used and shown to be helpful in a subset of patients ${ }^{41}$. With an increased severity in pain and evidence of phleboliths, LMWH is commonly prescribed. In recent years, newer oral anticoagulants such as rivaroxaban have become available. Rivaroxaban, a direct factor Xa inhibitor can prevent and treat venous thrombosis. At this time, all anticoagulants used in the standard of care for pediatric population are prescribed without formal FDA-approved indication. By directly inhibiting the coagulation factors, it should have clinical efficacy equivalent to heparins. Several case reports of pediatric 
and adult patients with slow-flow vascular malformations refractory to LMWH had improvement in LIC and pain from rivaroxaban ${ }^{42-44}$. Sirolimus therapy has also been shown to improve pain and LIC in some patients with slow-flow vascular malformations ${ }^{15,30}$.

\section{VTE prophylaxis and management of pain}

Management for VTE risk and pain due to microthrombi secondary to LIC begins with conservative management utilizing compression garments to help flow return, decrease stagnant blood flow and maintain integrity of the flaccid vessel ${ }^{45,46}$. The approach in our practice is that treatment for pain should be considered if there is evidence of LIC (D-dimer > 2 times ULN) and/or one or more of the following: decreased fibrinogen, decreased platelet count, presence of phleboliths, or localized pain. Anticoagulation may be initiated at the following recommended doses according to our practice:

- LMWH $0.5 \mathrm{mg} / \mathrm{kg} /$ dose every 12 hours, increase to $1 \mathrm{mg} / \mathrm{kg} /$ dose every 12 hours at 2 weeks if no or minimal benefit

OR

- Rivaroxaban $10 \mathrm{mg}$ PO daily, increase to $15 \mathrm{mg}$ at 2 weeks if no or minimal benefit (for patients $>50 \mathrm{~kg}$ and 15 years of age)

Duration of anticoagulation can vary from a minimum of 2 weeks to long-term treatment. Follow up is recommended at 2 weeks, 4 weeks, 12 weeks and every 3 months until off anticoagulation. This approach is currently being investigated in a multi-institutional prospective clinical trial. [Figure 3]

\section{3 | Perioperative risk with LIC}

\section{Risk stratification}

Prior to procedures, patients with extensive slow-flow vascular malformations should be evaluated by a hematologist. Laboratory values obtained should include: PT, aPTT, CBC, fibrinogen and d-dimer. Patients with significant elevation of d-dimer ( $>5$ times ULN) and hypofibrinogenemia $(<100 \mathrm{mg} / \mathrm{dl})$ or thrombocytopenia will likely benefit from anticoagulation ${ }^{7,9,10,26,47}$. The risk appears to be higher with more invasive procedures such as excision or extensive sclerotherapy ${ }^{48}$. If only d-dimer is elevated but venous ectasia is present, the patient may also be at risk of VTE following the procedure and the management must be individualized and compression garments at minimum may be utilized.

Approach to management of LIC perioperatively

Figure 3 summarizes our current approach to these patients. While LMWH has been the anticoagulant most used $^{49}$, some have experience with direct oral anticoagulants (DOAC) as an alternative ${ }^{42,44,50-52}$. DOAC may be a reasonable therapy post-operatively for patients at low risk of bleeding or who are strongly opposed to a subcutaneous injection.

\section{SUMMARY}

Bleeding and clotting in patients with vascular anomalies can come with significant morbidity and mortality. Therefore, it is essential to have an experienced multidisciplinary team which includes a hematologist wellversed in management of coagulopathy in patients with vascular anomalies. Most recommendations are based on small studies, case series and institutional experience. As the field grows and advances, larger prospective studies are needed to identify those patients who are at risk of coagulopathy and establish evidence-based guidelines for evaluation and treatment.

\section{CONFLICT OF INTERESTS}

The authors have no conflicts of interest to disclose.

\section{REFERENCES}


1. Ji Y, Yang K, Peng S, et al. Kaposiform haemangioendothelioma: clinical features, complications and risk factors for Kasabach-Merritt phenomenon. Br J Dermatol 2018;179(2):457-463. DOI: 10.1111/bjd.16601.

2. Croteau SE, Liang MG, Kozakewich HP, et al. Kaposiform hemangioendothelioma: atypical features and risks of Kasabach-Merritt phenomenon in 107 referrals. J Pediatr 2013;162(1):142-7. DOI: 10.1016/j.jpeds.2012.06.044.

3. Gruman A, Liang MG, Mulliken JB, et al. Kaposiform hemangioendothelioma without Kasabach-Merritt phenomenon. J Am Acad Dermatol 2005;52(4):616-22. DOI: 10.1016/j.jaad.2004.10.880.

4. Seo SK, Suh JC, Na GY, Kim IS, Sohn KR. Kasabach-Merritt syndrome: identification of platelet trapping in a tufted angioma by immunohistochemistry technique using monoclonal antibody to CD61. Pediatr Dermatol 1999;16(5):392-4. DOI: 10.1046/j.1525-1470.1999.00103.x.

5. Douma RA, Oduber CE, Gerdes VE, et al. Chronic pulmonary embolism in Klippel-Trenaunay syndrome. J Am Acad Dermatol 2012;66(1):71-7. DOI: 10.1016/j.jaad.2010.12.002.

6. Oduber CE, Young-Afat DA, van der Wal AC, van Steensel MA, Hennekam RC, van der Horst CM. The persistent embryonic vein in Klippel-Trenaunay syndrome. Vasc Med 2013;18(4):185-91. DOI: $10.1177 / 1358863 X 13498463$.

7. Oduber CE, van Beers EJ, Bresser P, van der Horst CM, Meijers JC, Gerdes VE. Venous thromboembolism and prothrombotic parameters in Klippel-Trenaunay syndrome. Neth J Med 2013;71(5):246-52. (https://www.ncbi.nlm.nih.gov/pubmed/23799311).

8. Keppler-Noreuil KM, Lozier JN, Sapp JC, Biesecker LG. Characterization of thrombosis in patients with Proteus syndrome. Am J Med Genet A 2017;173(9):2359-2365. DOI: 10.1002/ajmg.a.38311.

9. van Es J, Kappelhof NA, Douma RA, Meijers JCM, Gerdes VEA, van der Horst C. Venous thrombosis and coagulation parameters in patients with pure venous malformations. Neth J Med 2017;75(8):328-334. (https://www.ncbi.nlm.nih.gov/pubmed/29219827).

10. Sepulveda P, Zavala A, Zuniga P. Factors associated with thrombotic complications in pediatric patients with vascular malformations. J Pediatr Surg 2017;52(3):400-404. DOI: 10.1016/j.jpedsurg.2016.10.048.

11. Reis J, 3rd, Alomari AI, Trenor CC, 3rd, et al. Pulmonary thromboembolic events in patients with congenital lipomatous overgrowth, vascular malformations, epidermal nevi, and spinal/skeletal abnormalities and Klippel-Trenaunay syndrome. J Vasc Surg Venous Lymphat Disord 2018;6(4):511-516. DOI: 10.1016/j.jvsv.2018.01.015.

12. Harvey JA, Nguyen H, Anderson KR, et al. Pain, psychiatric comorbidities, and psychosocial stressors associated with Klippel-Trenaunay syndrome. J Am Acad Dermatol 2018;79(5):899-903. DOI: 10.1016/j.jaad.2018.05.1245.

13. Hermans C, Dessomme B, Lambert C, Deneys V. [Venous malformations and coagulopathy]. Ann Chir Plast Esthet 2006;51(4-5):388-93. DOI: 10.1016/j.anplas.2006.07.009.

14. Lee A, Driscoll D, Gloviczki P, Clay R, Shaughnessy W, Stans A. Evaluation and management of pain in patients with Klippel-Trenaunay syndrome: a review. Pediatrics 2005;115(3):744-9. DOI: 10.1542/peds.20040446 .

15. Mack JM, Verkamp B, Richter GT, Nicholas R, Stewart K, Crary SE. Effect of sirolimus on coagulopathy of slow-flow vascular malformations. Pediatr Blood Cancer 2019;66(10):e27896. DOI: 10.1002/pbc.27896.

16. Nakano TA, Zeinati C. Venous Thromboembolism in Pediatric Vascular Anomalies. Front Pediatr 2017;5:158. DOI: 10.3389/fped.2017.00158.

17. Drolet BA, Trenor CC, 3rd, Brandao LR, et al. Consensus-derived practice standards plan for complicated Kaposiform hemangioendothelioma. J Pediatr 2013;163(1):285-91. DOI: 10.1016/j.jpeds.2013.03.080. 
18. Croteau SE, Kozakewich HP, Perez-Atayde AR, et al. Kaposiform lymphangiomatosis: a distinct aggressive lymphatic anomaly. J Pediatr 2014;164(2):383-8. DOI: 10.1016/j.jpeds.2013.10.013.

19. Ji Y, Chen S, Peng S, Xia C, Li L. Kaposiform lymphangiomatosis and kaposiform hemangioendothelioma: similarities and differences. Orphanet J Rare Dis 2019;14(1):165. DOI: 10.1186/s13023-019-1147-9.

20. Fernandes VM, Fargo JH, Saini S, et al. Kaposiform lymphangiomatosis: unifying features of a heterogeneous disorder. Pediatr Blood Cancer 2015;62(5):901-4. DOI: 10.1002/pbc.25278.

21. Barclay SF, Inman KW, Luks VL, et al. A somatic activating NRAS variant associated with kaposiform lymphangiomatosis. Genet Med 2019;21(7):1517-1524. DOI: 10.1038/s41436-018-0390-0.

22. Le Cras TD, Mobberley-Schuman PS, Broering M, Fei L, Trenor CC, 3rd, Adams DM. Angiopoietins as serum biomarkers for lymphatic anomalies. Angiogenesis 2017;20(1):163-173. DOI: 10.1007/s10456-016$9537-2$.

23. North PE, Kahn T, Cordisco MR, Dadras SS, Detmar M, Frieden IJ. Multifocal lymphangioendotheliomatosis with thrombocytopenia: a newly recognized clinicopathological entity. Arch Dermatol 2004;140(5):599606. DOI: 10.1001/archderm.140.5.599.

24. Droitcourt C, Boccara O, Fraitag S, Favrais G, Dupuy A, Maruani A. Multifocal Lymphangioendotheliomatosis With Thrombocytopenia: Clinical Features and Response to Sirolimus. Pediatrics 2015;136(2):e51722. DOI: $10.1542 /$ peds.2014-2410.

25. Baselga E, Cordisco MR, Garzon M, Lee MT, Alomar A, Blei F. Rapidly involuting congenital haemangioma associated with transient thrombocytopenia and coagulopathy: a case series. Br J Dermatol 2008;158(6):1363-70. DOI: 10.1111/j.1365-2133.2008.08546.x.

26. Dompmartin A, Acher A, Thibon P, et al. Association of localized intravascular coagulopathy with venous malformations. Arch Dermatol 2008;144(7):873-7. DOI: 10.1001/archderm.144.7.873.

27. Hung JW, Leung MW, Liu CS, et al. Venous Malformation and Localized Intravascular Coagulopathy in Children. Eur J Pediatr Surg 2017;27(2):181-184. DOI: 10.1055/s-0036-1582241.

28. Wang P, Zhou W, Tao L, Zhao N, Chen XW. Clinical analysis of Kasabach-Merritt syndrome in 17 neonates. BMC Pediatr 2014;14:146. DOI: 10.1186/1471-2431-14-146.

29. Liu X, Li J, Qu X, et al. Clinical Outcomes for Systemic Corticosteroids Versus Vincristine in Treating Kaposiform Hemangioendothelioma and Tufted Angioma. Medicine (Baltimore) 2016;95(20):e3431. DOI: 10.1097/MD.0000000000003431.

30. Adams DM, Trenor CC, 3rd, Hammill AM, et al. Efficacy and Safety of Sirolimus in the Treatment of Complicated Vascular Anomalies. Pediatrics 2016;137(2):e20153257. DOI: 10.1542/peds.2015-3257.

31. Tlougan BE, Lee MT, Drolet BA, Frieden IJ, Adams DM, Garzon MC. Medical management of tumors associated with Kasabach-Merritt phenomenon: an expert survey. J Pediatr Hematol Oncol 2013;35(8):61822. DOI: 10.1097/MPH.0b013e318298ae9e.

32. Burleigh A, Kanigsberg N, Lam JM. Topical rapamycin (sirolimus) for the treatment of uncomplicated tufted angiomas in two children and review of the literature. Pediatr Dermatol 2018;35(5):e286-e290. DOI: 10.1111/pde.13596.

33. Zhang X, Yang K, Chen S, Ji Y. Tacrolimus ointment for the treatment of superficial kaposiform hemangioendothelioma and tufted angioma. J Dermatol 2019;46(10):898-901. DOI: 10.1111/1346-8138.15031.

34. Fernandez-Pineda I, Lopez-Gutierrez JC, Ramirez G, Marquez C. Vincristine-ticlopidine-aspirin: an effective therapy in children with Kasabach-Merritt phenomenon associated with vascular tumors. Pediatr Hematol Oncol 2010;27(8):641-5. DOI: 10.3109/08880018.2010.508299. 
35. Fernandez-Pineda I, Lopez-Gutierrez JC, Chocarro G, Bernabeu-Wittel J, Ramirez-Villar GL. Long-term outcome of vincristine-aspirin-ticlopidine (VAT) therapy for vascular tumors associated with KasabachMerritt phenomenon. Pediatr Blood Cancer 2013;60(9):1478-81. DOI: 10.1002/pbc.24543.

36. Moimeaux V, Taieb A, Legrain V, et al. Aspirin-ticlopidin in Kasabach-Merritt syndrome. Lancet 1992;340(8810):55. DOI: 10.1016/0140-6736(92)92470-z.

37. Lopez V, Marti N, Pereda C, et al. Successful management of Kaposiform hemangioendothelioma with Kasabach-Merritt phenomenon using vincristine and ticlopidine. Pediatr Dermatol 2009;26(3):365-6. DOI: 10.1111/j.1525-1470.2009.00923.x.

38. Hanna SA, Prasad A, Lee J, Achan P. Topical Versus Intravenous Administration of Tranexamic Acid in Primary Total Hip Arthroplasty: A Systematic Review and Meta-Analysis of Randomized Controlled Trials. Orthop Rev (Pavia) 2016;8(3):6792. DOI: 10.4081/or.2016.6792.

39. O'Rafferty C, O'Regan GM, Irvine AD, Smith OP. Recent advances in the pathobiology and management of Kasabach-Merritt phenomenon. Br J Haematol 2015;171(1):38-51. DOI: 10.1111/bjh.13557.

40. Phillips WG, Marsden JR. Kasabach-Merritt syndrome exacerbated by platelet transfusion. J R Soc Med 1993;86(4):231-2. (https://www.ncbi.nlm.nih.gov/pubmed/8505736).

41. Nguyen JT, Koerper MA, Hess CP, et al. Aspirin therapy in venous malformation: a retrospective cohort study of benefits, side effects, and patient experiences. Pediatr Dermatol 2014;31(5):556-60. DOI: 10.1111/pde.12373.

42. Mack JM, Richter GT, Crary SE. Effectiveness and Safety of Treatment with Direct Oral Anticoagulant Rivaroxaban in Patients with Slow-Flow Vascular Malformations: A Case Series. Lymphat Res Biol 2018;16(3):278-281. DOI: 10.1089/lrb.2017.0029.

43. Randrianarisoa E, Kopp HG, Balletshofer BM, et al. Management of disseminated intravascular coagulopathy with direct factor Xa inhibitor rivaroxaban in Klippel-Trenaunay syndrome. Blood Coagul Fibrinolysis 2013;24(7):766-70. DOI: 10.1097/MBC.0b013e3283626238.

44. Vandenbriele C, Vanassche T, Peetermans M, Verhamme P, Peerlinck K. Rivaroxaban for the treatment of consumptive coagulopathy associated with a vascular malformation. J Thromb Thrombolysis 2014;38(1):1213. DOI: $10.1007 / \mathrm{s} 11239-013-1024-7$.

45. Langbroek GB, Horbach SE, van der Vleuten CJ, Ubbink DT, van der Horst CM. Compression therapy for congenital low-flow vascular malformations of the extremities: A systematic review. Phlebology 2018;33(1):513. DOI: $10.1177 / 0268355516684694$.

46. Dasgupta R, Patel M. Venous malformations. Semin Pediatr Surg 2014;23(4):198-202. DOI: 10.1053/j.sempedsurg.2014.06.019.

47. Zhuo KY, Russell S, Wargon O, Adams S. Localised intravascular coagulation complicating venous malformations in children: Associations and therapeutic options. J Paediatr Child Health 2017;53(8):737741. DOI: $10.1111 /$ jpc.13461.

48. Mack JM, Pierce CD, Richter GT, et al. Analyzing coagulation dynamics during treatment of vascular malformations with thromboelastography. Pediatr Blood Cancer 2021;68(2):e28824. DOI: 10.1002/pbc.28824.

49. Ricci KW, Chute C, Hammill AM, Dasgupta R, Patel M. Retrospective study of hematologic complications in patients with slow-flow vascular malformations undergoing sclerotherapy. Pediatr Blood Cancer 2020:e28277. DOI: 10.1002/pbc.28277.

50. Binet Q, Lambert C, Hermans C. Dabigatran etexilate in the treatment of localized intravascular coagulopathy associated with venous malformations. Thromb Res 2018;168:114-120. DOI: 10.1016/j.thromres.2018.06.013. 
51. Ardillon L, Lambert C, Eeckhoudt S, Boon LM, Hermans C. Dabigatran etexilate versus low-molecular weight heparin to control consumptive coagulopathy secondary to diffuse venous vascular malformations. Blood Coagul Fibrinolysis 2016;27(2):216-9. DOI: 10.1097/MBC.0000000000000412.

52. Yasumoto A, Ishiura R, Narushima M, Yatomi Y. Successful treatment with dabigatran for consumptive coagulopathy associated with extensive vascular malformations. Blood Coagul Fibrinolysis 2017;28(8):670674. DOI: $10.1097 / \mathrm{MBC} .0000000000000666$.

Table 1: Clinical features of coagulopathy with various vascular anomalies

\begin{tabular}{|c|c|c|c|}
\hline Features & $K M P$ & $K L A$ & $M L T$ \\
\hline Platelets & & & -- \\
\hline Fibrinogen & $--\square$ & $--\square$ & - \\
\hline D-dimer & $--\square$ & $--\square$ & - \\
\hline Other distinguishing features & Enlarges after birth; infiltrative & Involves multiple sites and organs & Lungs, skin and GI t \\
\hline Bleeding risk & Minimal & High & High \\
\hline
\end{tabular}

Table 2: Recommendation for Management of Unresectable KHE with KMP

First line medical management:

Start oral prednisolone or IV methylprednisolone $2 \mathrm{mg} / \mathrm{kg} /$ day plus sirolimus $0.8 \mathrm{mg} / \mathrm{m} 2 /$ day twice daily (target trough 8-12)

Begin to taper dose once KMP resolves (platelets >100K, fibrinogen >100) to off or to lowest tolerable dose

- Vincristine IV $0.05 \mathrm{mg} / \mathrm{kg}$ once weekly may also be considered instead of sirolimus based on family and provider preferenceSupportive Care:

- Cryoprecipitate for active bleeding, planned invasive procedure and fibrinogen $<100 \mathrm{mg} / \mathrm{dL}$

- Platelet transfusion ONLY for active bleeding or planned invasive procedures if $<50,000 / \mathrm{mm}^{3}$

- PRBC transfusion for severe and/or symptomatic anemia (usually $\mathrm{Hb}<8 \mathrm{~g} / \mathrm{dL}$ ) Second line for recurrent or refractory KMP:

Add aspirin $10 \mathrm{mg} / \mathrm{kg} /$ day and/or ticlopidine $10 \mathrm{mg} / \mathrm{kg} /$ day

Figure 1 Laboratory trend for Case 1 showing fibrinogen and d-dimer over time and in relation to treatments. Also depicted are transfusions of platelets $(*)$ and cryoprecipitate (\#).

Figure 2 Extensive venous malformation of the anterior hip (left) and posterior back (right).

Figure 3 Institutional guideline for perioperative management of slow-flow vascular malformations. This is not consensus-driven or based on high-quality clinical trial data. 


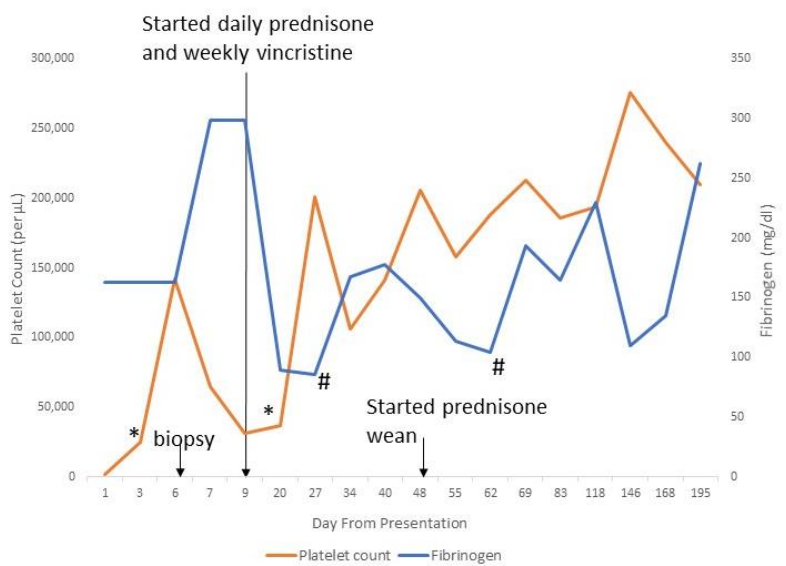




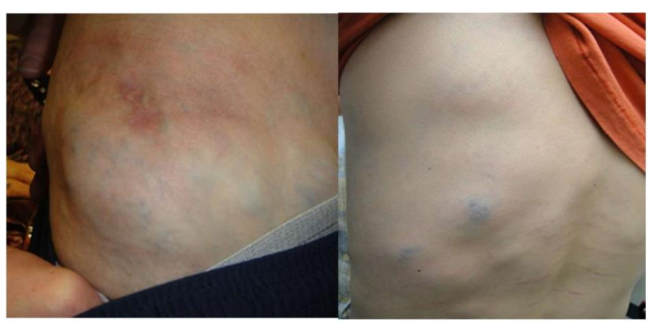



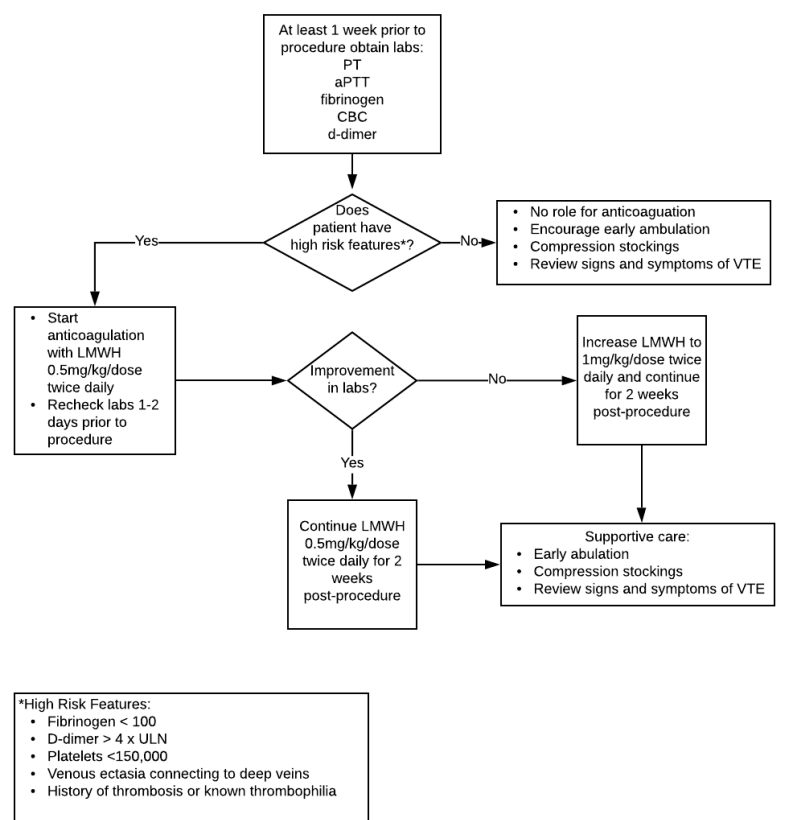